\title{
Experimental Pneumococcal and Staphylococcal Sepsis: Effects of Hydrocortisone and Phenoxybenzamine upon Mortality Rates*
}

\author{
Hugh G. Robson and Leighton E. Cluff $\dagger$ \\ (From the Division of Infectious Disease and Clinical Immunology, Department of Medicine, \\ Johns Hopkins University School of Medicine, Baltimore, Md.)
}

The institution of appropriate antimicrobial therapy after a critical period in infectious diseases of man and experimental animals may fail to prevent death (1-6). In these circumstances, death is probably attributable to biochemical or physiologic derangements that are not reversed by elimination of the infecting microorganisms (5). In some instances the lethal outcome is related to the occurrence of acute circulatory insufficiency or shock (3).

Adrenergic blocking agents and adrenal corticosteroids have been used to reduce mortality from shock due to trauma, hemorrhage, and endotoxin (7-11). Adrenal corticosteroids may alter manifestations of severe infection such as fever, toxicity, and inflammatory response to promote a sense of well-being and hasten recovery (12-15). It has not been firmly established, however, that either adrenal corticosteroids or adrenergic blocking agents can reduce mortality from severe bacterial infections.

Previously, it was found that pneumococcal sepsis in rabbits was associated with progressively decreasing cardiac output, progressively rising peripheral vascular resistance, and terminal hypotension (3). Recent studies have shown that staphylococcal sepsis in rabbits produces opposite effects, with progressively increasing cardiac output, progressively decreasing peripheral vascular

* Submitted for publication May 3, 1965 ; accepted June 2, 1966.

Supported by a training grant from the National Institute of Allergy and Infectious Disease, Bethesda, a contract with the Army Biological Laboratories, Frederick, Md., and a contract with the Commission on Streptococcal and Staphylococcal Disease, Armed Forces Epidemiological Board, Office of the Surgeon General, Washington, $\mathrm{D}$. C.

$\dagger$ Address requests for reprints to Dr. Leighton E. Cluff, Dept. of Medicine, University of Florida College of Medicine, Gainesville, Fla. 32603. resistance, and terminal hypotension (16). These findings suggest that the effects of adrenal corticosteroid or adrenergic blocking agents upon the outcome of these infections might not be the same.

Accordingly, studies were undertaken to investigate the effects of these forms of adjunctive therapy upon the mortality rates of experimental staphylococcal and pneumococcal infections in rabbits. They show that in pneumococcal infection hydrocortisone administered with penicillin prevents death not prevented by penicillin alone, whereas phenoxybenzamine is ineffective in preventing death. In staphylococcal infection, phenoxybenzamine plus methicillin prevents death not prevented by methicillin alone, whereas hydrocortisone is ineffective.

\section{Methods}

Pneumococcus. The Type I strain I-SV 1 was used. Its virulence for rabbits was maintained by anaerobic storage in defibrinated rabbit blood and frequent mouse and rabbit passage. The infecting inoculum was $1.0 \mathrm{ml}$ of an 8-hour rabbit blood-trypticase soy broth culture containing approximately $2.5 \times 10^{\circ}$ viable pneumococci. All infections were produced by intraperitoneal injection.

Staphylococcus. A coagulase positive, alpha toxin producing Staphylococcus aureus (Lafferty), bacteriophage type $80 / 81$ was used. This strain was penicillin $G$ resistant. The infecting inoculum was $1.0 \mathrm{ml}$ of an 8-hour trypticase soy broth culture containing $5 \times 10^{8}$ viable staphylococci. Infection was produced by the intravenous route.

Experimental animals. Male New Zealand white rabbits weighing from 2.0 to $2.7 \mathrm{~kg}$ were used. Febrile responses were measured with rectal probes and a TeleThermometer. ${ }^{1}$ Rabbits were housed in air-conditioned quarters and allowed food and water ad libitum.

Penicillin. Penicillin was injected intravenously in a dose of $300,000 \mathrm{U}$ of crystalline potassium penicillin $\mathrm{G}$ and intramuscularly in a dose of $300,000 \mathrm{U}$ of procaine penicillin $\mathrm{G}$.

\footnotetext{
1 Yellow Springs Instrument Co., Yellow Springs, Ohio.
} 
TABLE I

Effect of time of treatment with penicillin or feizicillin plus hydrocortisone upon mortality rate in pneumococcal bacteremia

\begin{tabular}{|c|c|c|c|c|c|c|c|c|}
\hline \multirow{3}{*}{$\frac{\text { Group }}{\text { Control }}$} & \multirow{3}{*}{$\begin{array}{c}\begin{array}{c}\text { No. of } \\
\text { animals }\end{array} \\
118\end{array}$} & \multicolumn{6}{|c|}{ Deaths and per cent mortality* } & \multirow{3}{*}{$\begin{array}{l}\text { Total per cent } \\
\text { mortality }\end{array}$} \\
\hline & & \multicolumn{2}{|c|}{0 to 24 hours } & \multicolumn{2}{|c|}{24 to 48 hours } & \multicolumn{2}{|c|}{48 to 120 hours } & \\
\hline & & 63 & 53 & 22 & 19 & 20 & 17 & \\
\hline PCN, 6 hours $\dagger$ & 90 & 37 & $41 x^{2}=15.3$ & 4 & 4 & 1 & 1 & $47 x^{2}=5.14$ \\
\hline $\mathrm{PCN}+\mathrm{H}^{++}, 6$ hours & 45 & 3 & $7 \mathrm{p}<0.001$ & 1 & 2 & 2 & 4 & $13 \mathrm{p}<0.05$ \\
\hline PCN, 8 hours & 18 & 11 & $61 x^{2}=6.00$ & 0 & 0 & 0 & 0 & $61 x^{2}=2.81$ \\
\hline $\mathrm{PCN}+\mathrm{H}, 8$ hours $\ddagger$ & 18 & 3 & $17 \mathrm{p}<0.02$ & 0 & 0 & 2 & 11 & $28 \mathrm{p}>0.05$ \\
\hline PCN, 10 hours & 19 & 9 & 47 & 0 & 0 & 1 & 5 & 53 \\
\hline $\mathrm{PCN}+\mathrm{H}, 10$ hours & 19 & 7 & 37 & 1 & 5 & 1 & 5 & 47 \\
\hline PCN, 12 hours & 17 & 8 & 47 & 0 & 0 & 2 & 12 & 59 \\
\hline $\mathrm{PCN}+\mathrm{H}, 12$ hours & 16 & 7 & 44 & 0 & 0 & 1 & 6 & 50 \\
\hline
\end{tabular}

* Deaths are indicated in the left-hand column under each heading, and per cent mortality in the right-hand column.

$t$ Hours after infection. PCN = penicillin, and $\mathrm{H}=$ hydrocortisone.

$\ddagger$ All hydrocortisone doses $=40 \mathrm{mg}$ per $\mathrm{kg}$.

Methicillin. Methicillin was administered in seven intramuscular injections of $50 \mathrm{mg}$ per $\mathrm{kg}$ per dose, at 8-hour intervals, except where noted differently. Injection volumes were adjusted to $1.0 \mathrm{ml}$ in isotonic saline $(0.85 \% \mathrm{NaCl})$ and used within 15 minutes of preparation.

Phenoxybenzamine. A stock solution of phenoxybenzamine $\mathrm{HCl}$ was prepared by dissolving the powder to a concentration of $10 \mathrm{mg}$ per $\mathrm{ml}$ in a solvent composed of equal parts of propylene glycol and 95\% ethanol made slightly acid $(0.05 \mathrm{~N})$ with concentrated sulfuric acid. Immediately before administration the stock solution was diluted 1:10 with isotonic saline. All doses were $1.0 \mathrm{mg}$ per $\mathrm{kg}$ and were injected intravenously over 30 to 60 seconds. Times of administration are described in the text.

Hydrocortisone. Hydrocortisone succinate was dissolved immediately before use in isotonic saline. The drug was administered intravenously as described in the text.

Blood cultures. Blood samples were obtained from polyvinyl catheters inserted through the right external jugular vein into the superior vena cava, as described previously (3). Serial tenfold dilutions were made in isotonic saline and viable counts were determined by counting the colonies grown in trypticase soy agar pour plates. In pneumococcal infection all pour plates contained $1 \%$ rabbit blood and an excess of penicillinase where indicated. All plates were incubated for 24 hours at $37^{\circ} \mathrm{C}$ under aerobic conditions.

Quantitative organ cultures. Organs to be cultured were promptly removed from animals sacrificed with pentobarbital or immediately after death from infection. Specimens of both lungs, both kidneys, the spleen, and a $10-\mathrm{g}$ portion of liver were washed in sterile cold isotonic saline and ground in a Virtis 45 homogenizer. ${ }^{2}$ Samples were diluted, plated, and counted as above.

2 The Virtis Co., Gardiner, N. Y.

\section{Results}

\section{Pneumococcal infection}

Lethality of untreated pneumococcal infection. The total mortality of untreated pneumococcal infection in rabbits was $89 \%$ (Table I). About half of the animals (53\%) died within the first 24 hours, about one-fifth (19\%) within 24 to 48 hours, and another one-fifth $(17 \%)$ between 48 and 120 hours after the onset of infection. Most of the animals surviving to 120 hours and then sacrificed had levels of pneumococcal bacteremia of about $10^{2}$ microorganisms per $\mathrm{ml}$. Although complete autopsies were not always performed, acute peritonitis and renal medullary abscesses were frequently noted.

Effect of penicillin treatment upon lethality. Previously it was reported that death from pneumococcal sepsis in rabbits could be prevented if penicillin was administered within 4 hours of onset of infection (3). Treatment after 4 hours failed to prevent death expected to occur within the first 24 hours of infection. Experiments to re-examine these observations were carried out before the effect of hydrocortisone and phenoxybenzamine upon the mortality rate was studied.

Penicillin was administered to groups of rabbits at intervals of $6,8,10$, and 12 hours after infection induced as in the previous experiment. Equal numbers of untreated control animals were always included in each experiment. The times at which deaths occurred were noted, and experiments were terminated after 120 hours. 
The group of rabbits receiving penicillin 6 hours after infection had a total mortality of $47 \%$ ( Table I). Almost all of these deaths $(41 \%)$ occurred within the first 24 hours after infection. Animals living through this critical interval had an excellent chance of permanent survival. The 24-hour mortality within the group receiving antimicrobial therapy as early as the sixth hour, however, represented no improvement when compared to the mortality at 24 hours $(53 \%)$ in animals receiving penicillin at 8,10 , and 12 hours after infection. In each instance, about half of the animals died within 24 hours of onset of infection $(61,47$, and $47 \%$, respectively). Penicillin treatment at these times prevented most of the deaths expected to occur between 24 and 120 hours, but it was completely ineffective in preventing earlier deaths.

Prevention of lethality by hydrocortisone. To determine if glucocorticoid therapy administered with penicillin would result in a different mortality rate than with penicillin alone, we performed the following experiments.

Groups of rabbits were treated concurrently with penicillin and hydrocortisone, $40 \mathrm{mg}$ per $\mathrm{kg}$, at intervals of $6,8,10$, and 12 hours after onset of pneumococcal infection. The same dose of hydrocortisone was repeated 24 hours after the initial dose. Untreated and penicillin-treated groups of animals were included as controls.

The total mortality rate of the group of rabbits treated at 6 hours with hydrocortisone and penicillin was $13 \%$, a value significantly lower than that of rabbits treated only with penicillin (Table I). The 24-hour mortality in animals receiving hydro- cortisone and penicillin at 6 hours was $7 \%$, again significantly lower than that of the group receiving penicillin alone. Rabbits receiving both hydrocortisone and penicillin at the eighth hour of pneumococcal bacteremia had a total mortality of $28 \%$. This was not significantly lower than that $(61 \%)$ of the group treated with penicillin alone. The 24-hour mortality rate of $17 \%$ was significantly less in animals treated at the eighth hour with penicillin and hydrocortisone than in animals treated only with penicillin $(61 \%)$. Bacterial counts in viscera of animals treated with hydrocortisone and penicillin did not differ from those of rabbits treated with penicillin alone.

Hydrocortisone dose-response relationship. The amount of hydrocortisone required to protect against lethality in penicillin-treated pneumococcal bacteremia was investigated by treating groups of rabbits 6 hours after infection with doubling doses of hydrocortisone from 2.5 to $40 \mathrm{mg}$ per $\mathrm{kg}$ and concurrently with penicillin. The same dose of hydrocortisone was administered 24 hours after the initial dose. Untreated animals and rabbits treated at 6 hours with penicillin served as controls.

The group of rabbits with pneumococcal sepsis receiving the lowest hydrocortisone dose $(2.5 \mathrm{mg}$ per $\mathrm{kg}$ ) concurrently with penicillin had an overall mortality rate of $43 \%$, which was not different from the results obtained with penicillin therapy alone (Table II). Similarly, this dose of hydrocortisone produced no significant reduction in the mortality at 24 hours after infection (25\%). A moderate but not significant reduction in total mortality to $30 \%$ was observed in the group of rabbits that received hydrocortisone, $5 \mathrm{mg}$ per $\mathrm{kg}$,

TABLE II

Effect of dose of hydrocortisone upon mortality rate in penicillin-treated pneumococcal bacteremia*

\begin{tabular}{|c|c|c|c|c|c|c|c|c|}
\hline \multirow{2}{*}{ Group } & \multirow{2}{*}{$\begin{array}{c}\text { No. of } \\
\text { animals }\end{array}$} & \multicolumn{6}{|c|}{ Deaths and per cent mortality $\dagger$} & \multirow{2}{*}{$\begin{array}{c}\text { Total per cent } \\
\text { mortality }\end{array}$} \\
\hline & & \multicolumn{2}{|c|}{0 to 24 hours } & \multicolumn{2}{|c|}{24 to 48 hours } & \multicolumn{2}{|c|}{48 to 120 hours } & \\
\hline $\begin{array}{l}\text { Control } \\
\text { PCN } \\
\text { PCN + H, 2.5 } \\
\text { PCN + H, 5 }\end{array}$ & $\begin{array}{r}118 \\
90 \\
28 \\
30\end{array}$ & $\begin{array}{r}63 \\
37 \\
7 \\
4\end{array}$ & $\begin{array}{l}53 \\
41 \\
25 \\
13 x^{2}=6.5 \\
p<0.02\end{array}$ & $\begin{array}{r}22 \\
4 \\
1 \\
4\end{array}$ & $\begin{array}{r}19 \\
4 \\
4 \\
13\end{array}$ & $\begin{array}{r}20 \\
1 \\
4 \\
1\end{array}$ & $\begin{array}{r}17 \\
1 \\
14 \\
3\end{array}$ & $\begin{array}{l}89 \\
47 \\
43 \\
30\end{array}$ \\
\hline $\mathrm{PCN}+\mathrm{H}, 10$ & 36 & 5 & $\begin{array}{r}14 \mathrm{x}^{2}=4.1 \\
\mathrm{p}<0.05\end{array}$ & 2 & 6 & 2 & 6 & $\begin{array}{r}24 x^{2}=7.6 \\
p<0.01\end{array}$ \\
\hline $\mathrm{PCN}+\mathrm{H}, 20$ & 45 & 2 & $\begin{array}{c}4 x^{2}=11.2 \\
p<0.01\end{array}$ & 0 & 0 & 4 & 9 & $\begin{array}{c}13 \mathrm{x}^{2}=13.21 \\
\mathrm{p}<0.01\end{array}$ \\
\hline $\mathrm{PCN}+\mathrm{H}, 40$ & 45 & 3 & 7 & 1 & 2 & 2 & 4 & $13^{p}$ \\
\hline
\end{tabular}

* All doses given 6 hours after infection.

$\dagger$ Indicated as in Table I.

$\ddagger \mathrm{H}=$ hydrocortisone, milligrams per kilogram. 
concurrently with penicillin. The mortality after 24 hours $(13 \%)$ was, however, significantly lower than that of animals treated only with penicillin $(41 \%)$.

The group of rabbits receiving $10 \mathrm{mg}$ hydrocortisone per $\mathrm{kg}$ concurrently with penicillin had an over-all mortality of $24 \%$, which was significantly less than that of animals treated only with penicillin. Similarly, the 24-hour mortality in this group was lower than that of animals receiving only penicillin therapy.

A cortisol dose of $20 \mathrm{mg}$ per $\mathrm{kg}$ produced a very striking alteration in the pattern of lethality. The total mortality rate $(13 \%)$ was significantly lower, as was the mortality at 24 hours (4\%), when compared with the mortality of animals treated only with penicillin (47 and $41 \%$, respectively). Increasing the dose of hydrocortisone to $40 \mathrm{mg}$ per $\mathrm{kg}$ produced no further reduction in mortality (Table II).

Course of bacteremia after treatment with penicillin and hydrocortisone. A relationship has been observed between the quantitative level of bacteremia and outcome in experimental pneumococcal infection (3). The following studies were done, therefore, to determine if the effect of hydrocortisone upon mortality was attributable to an alteration of the effect of penicillin upon pneumococcal bacteremia.

Groups of rabbits were treated with penicillin alone or with penicillin and hydrocortisone, $40 \mathrm{mg}$ per $\mathrm{kg}$, at 4 or 6 hours after infection. Quantitative blood cultures were made at 2 -hour intervals after the start of therapy.

Penicillin administered 4 hours after the onset of infection produced a slow decline in the number of viable pneumococci in the blood, and 8 hours atter treatment several animals continued to demonstrate bacteremia. The effect upon bacteremia after administration of penicillin plus hydrocortisone was the same, and a similar number of animals continued to manifest bacteremia 8 hours after beginning therapy.

Institution of therapy 6 -hours after infection resulted in a slower decline of viable organisms, but again the rate of disappearance of bacteria from the circulation was the same in groups receiving penicillin with or without hydrocortisone. Blood cultures of only two animals became sterile within 8 hours of treatment; both had an initial bacteremia of less than $10^{6}$ microorganisms per $\mathrm{ml}$, and both received only penicillin.

Effect of phenoxybenzamine upon mortality. To determine if phenoxybenzamine would alter the mortality in penicillin-treated pneumococcal bacteremia we performed the following experiment.

Pneumococcal bacteremia was produced in groups of rabbits as described above. Phenoxybenzamine was administered to one group of animals 1 hour before the inception of infection, whereas another group received the same dose 6 hours after infection. These two groups and an additional group not given phenoxybenzamine received penicillin 6 hours after infection. An untreated control group was included in the experiment. Deaths were recorded as before.

About half $(48 \%)$ of the untreated animals died within the first 24 hours, and the total mortality was $91 \%$ (Table III). The group that received only penicillin at 6 hours had a mortality of $19 \%$ at 24 hours and a total mortality of $36 \%$. The mortalities at 24 hours in the groups treated with penicillin at 6 hours and phenoxybenzamine either 1 hour before or 6 hours after infection were 21

TABLE III

Effect of penicillin and phenoxybenzamine upon mortality rates in pneumococcal infection of rabbits

\begin{tabular}{|c|c|c|c|c|c|c|c|c|}
\hline \multirow{2}{*}{ Group* } & \multirow{2}{*}{$\begin{array}{l}\text { No. of } \\
\text { animals }\end{array}$} & \multicolumn{6}{|c|}{ Deaths and per cent mortality } & \multirow{2}{*}{$\begin{array}{l}\text { Total per cent } \\
\text { mortality }\end{array}$} \\
\hline & & \multicolumn{2}{|c|}{0 to 24 hours } & \multicolumn{2}{|c|}{24 to 48 hours } & \multicolumn{2}{|c|}{48 to 120 hours } & \\
\hline $\begin{array}{l}\text { Control } \\
\text { PCN }(+6) \\
\mathrm{D}(-1), \\
\quad \mathrm{PCN}(+6)\end{array}$ & $\begin{array}{l}44 \\
31 \\
24\end{array}$ & $\begin{array}{r}21 \\
6 \\
5\end{array}$ & $\begin{array}{l}48 \\
19 \\
21\end{array}$ & $\begin{array}{r}11 \\
2 \\
0\end{array}$ & $\begin{array}{r}25 \\
7 \\
0\end{array}$ & $\begin{array}{l}8 \\
3 \\
2\end{array}$ & $\begin{array}{r}18 \\
10 \\
8\end{array}$ & $\begin{array}{l}91 \\
36 \\
29\end{array}$ \\
\hline $\begin{array}{l}\mathrm{D}(+6) \\
\quad \mathrm{PCN}(+6)\end{array}$ & 23 & 5 & 22 & 2 & 9 & 2 & 9 & 39 \\
\hline
\end{tabular}

* $\mathrm{PCN}=$ penicillin $\mathrm{G} ; \mathrm{D}=$ phenoxybenzamine (Dibenzyline), $1.0 \mathrm{mg}$ per $\mathrm{kg}$ iv. Numbers in parentheses refer to hours before $(-)$ or after $(+)$ inception of infection.

$\dagger$ Indicated as in Table I. 
TABLE IV

Effect of methicillin, hydrocortisone, and phenoxybenzamine upon mortality rate of Staphylococcus aureus infection in rabbits

\begin{tabular}{|c|c|c|c|c|c|c|c|c|}
\hline \multirow{3}{*}{$\frac{\text { Group* }}{\text { Control }}$} & \multirow{3}{*}{$\begin{array}{c}\begin{array}{c}\text { No. of } \\
\text { animals }\end{array} \\
98\end{array}$} & \multicolumn{6}{|c|}{ Deaths and per cent mortalityt } & \multirow{3}{*}{$\begin{array}{l}\text { Total per cent mortality } \\
97\end{array}$} \\
\hline & & \multicolumn{2}{|c|}{0 to 24 hours } & \multicolumn{2}{|c|}{24 to 48 hours } & \multicolumn{2}{|c|}{48 to 120 hours } & \\
\hline & & 80 & 82 & 9 & 9 & 6 & 6 & \\
\hline Meth (4) & 10 & $\mathbf{0}$ & $\mathbf{0}$ & $\mathbf{0}$ & $\mathbf{0}$ & $\mathbf{0}$ & $\mathbf{0}$ & $\mathbf{0}$ \\
\hline Meth + H(4) & 10 & $\mathbf{0}$ & 0 & 0 & $\mathbf{0}$ & $\mathbf{0}$ & $\mathbf{0}$ & $\mathbf{0}$ \\
\hline Meth (8) & 10 & 1 & 10 & $\mathbf{0}$ & $\mathbf{0}$ & $\mathbf{0}$ & 0 & 10 \\
\hline Meth + H(8) & 10 & 1 & 10 & $\mathbf{0}$ & $\mathbf{0}$ & $\mathbf{0}$ & $\mathbf{0}$ & 10 \\
\hline Meth (10) & 28 & 12 & 43 & 1 & 4 & 1 & 4 & 50 \\
\hline Meth + H(10) & 28 & 11 & 39 & $\mathbf{0}$ & $\mathbf{0}$ & 1 & 4 & 43 \\
\hline$D+\operatorname{Meth}(10)$ & 20 & 1 & $\begin{array}{c}5 x^{2}=6.65 \\
p<0.01\end{array}$ & $\mathbf{0}$ & 0 & 0 & 0 & $\begin{array}{c}5 x^{2}=9.48 \\
p<0.01\end{array}$ \\
\hline Meth (12) & 28 & 13 & 46 & 4 & 14 & 1 & 4 & 64 \\
\hline Meth + H(12) & 28 & 11 & 39 & 3 & 11 & $\mathbf{0}$ & $\mathbf{0}$ & 50 \\
\hline D + Meth (12) & 20 & 1 & $\begin{array}{c}5 x^{2}=7.80 \\
p<0.01\end{array}$ & 1 & 5 & 0 & 0 & $10 x^{2}=12.00, p<0.01$ \\
\hline Meth (14) & 20 & 12 & 60 & 1 & 5 & $\mathbf{0}$ & $\mathbf{0}$ & $65 x^{2}=17.9, p<0.01$ \\
\hline Meth + H(14) & 20 & 9 & 45 & 4 & 20 & 2 & 10 & 75 \\
\hline $\mathrm{D}+$ Meth (14) & 21 & 8 & 38 & 3 & 14 & $\mathbf{0}$ & $\mathbf{0}$ & 52 \\
\hline
\end{tabular}

* Meth $=$ methicillin, $50 \mathrm{mg}$ per $\mathrm{kg}$ per dose $\mathrm{H}=$ hydrocortisone, $20 \mathrm{mg}$ per $\mathrm{kg}$ per dose and $\mathrm{D}=$ phenoxybenzamine (Dibenzyline), 1.0 $\mathrm{mg}$ per $\mathrm{kg}$ pretreatment. Numbers in parentheses refer to time (hours after infection) of beginning therapy.

$t$ Indicated as in Table $I$.

and $22 \%$, respectively. Total mortalities in these groups were 29 and $39 \%$, respectively. There was no significant difference in mortality between the groups treated with phenoxybenzamine and penicillin and the group treated only with penicillin.

\section{Staphylococcal infection}

Lethality of untreated staphylococcal infection. After the intravenous injection of staphylococci, as described in Methods, the total mortality during 120 hours of observation was $97 \%$ (Table IV). About four-fifths (82\%) of the rabbits died within the first 24 hours of infection. Between 24 to 48 and 48 to 120 hours the additional mortalities were 9 and $6 \%$, respectively. Within the first 8 hours of lethal staphylococcal infection, an average temperature elevation of $2^{\circ} \mathrm{C}$ was observed.

Effect of time of methicillin therapy upon mortality. To determine the relationship between the time of initiation of methicillin therapy and the mortality rate we performed the following experiment. Staphylococcal infection was produced in groups of rabbits, and methicillin therapy was begun at intervals of $4,8,10,12$, and 14 hours after onset of infection as described in Methods. An untreated control group was included in each experiment. The times at which rabbits died were noted.
When methicillin therapy was initiated between 4 and 8 hours of infection, no deaths occurred (Table IV). The mortality was $10 \%$ when methicillin was administered beginning 8 hours after infection, with death occurring in the first 24 hours. Administration of methicillin begun at 10 hours after infection resulted in a total mortality of $50 \%$. Forty-three per cent of animals died within the first 24 hours. The initiation of antimicrobial therapy at 12 and 14 hours after infection was followed by total mortalities of 64 and $65 \%$, and 46 to $60 \%$ of animals died within 24 hours of onset of infection.

Treatment with methicillin begun 4 hours after onset of infection prevented all deaths. Delay in initiating specific antibacterial therapy until 8, 10 , 12 , or 14 hours after the onset of infection was associated with a rising mortality rate. Most of the deaths associated with a delay in institution of therapy occurred within the first 24 hours of the infection. Therapy delayed as long as 14 hours, however, prevented some deaths when compared to the control group (65 and $97 \%$ mortality, respectively). If therapy was withheld past the fourteenth hour of infection, many animals died without having received methicillin.

Effect of dose of methicillin upon lethality. To determine if deaths occurring after therapy was delayed might be prevented by larger doses of 
TABLE V

Effect of dose of methicillin upon mortahty of rabbits with staphylococcal infection

\begin{tabular}{|c|c|c|c|c|c|c|c|c|}
\hline \multirow{3}{*}{$\frac{\text { Group* }}{\text { Control }}$} & \multirow{3}{*}{$\begin{array}{c}\begin{array}{c}\text { No. of } \\
\text { animals }\end{array} \\
20\end{array}$} & \multicolumn{6}{|c|}{ Deaths and per cent mortality $\dagger$} & \multirow{3}{*}{$\begin{array}{c}\begin{array}{c}\text { Total per cent } \\
\text { mortality }\end{array} \\
95\end{array}$} \\
\hline & & \multicolumn{2}{|c|}{0 to 24 hours } & \multicolumn{2}{|c|}{24 to 48 hours } & \multicolumn{2}{|c|}{48 to 120 hours } & \\
\hline & & 15 & 75 & 2 & 10 & 2 & 10 & \\
\hline Meth A & 20 & 12 & 60 & 0 & 0 & 0 & 0 & 60 \\
\hline Meth B & 20 & 12 & 60 & 0 & 0 & 0 & 0 & 60 \\
\hline
\end{tabular}

* Meth $\mathrm{A}=$ seven consecutive 8 hourly im doses of methicillin, $50 \mathrm{mg}$ per $\mathrm{kg}$; Meth $\mathrm{B}=$ five consecutive 2 hourly doses of methicillin, $50 \mathrm{mg}$ per $\mathrm{kg}$, followed by five identical doses at 8 -hour intervals.

$\dagger$ Indicated as in Table I.

methicillin, we administered it to two groups of rabbits beginning 12 hours after the onset of staphylococcal infection. One group of rabbits received the standard course of methicillin therapy described previously. The second group received five consecutive methicillin injections of $50 \mathrm{mg}$ per $\mathrm{kg}$ at 2-hour intervals followed by five further doses at 8-hour intervals.

The total mortality in the untreated group was 95\% (Table V). Most of the deaths occurred within 24 hours of onset of infection $(75 \%)$. The total mortalities in the methicillin-treated groups were identical $(60 \%)$, and all deaths occurred during the first 24 hours of infection.

Effect of hydrocortisone upon lethality. Staphylococcal sepsis was produced in groups of rabbits as described previously. Hydrocortisone, $20 \mathrm{mg}$ per $\mathrm{kg}$, was administered concurrently with the initiation of methicillin therapy to groups of rabbits at $4,8,10,12$, and 14 hours after infection. The same dose of hydrocortisone was repeated twice at 8-hour intervals after the initial dose. Methicillin therapy was completed according to the regimen described previously. Untreated and methicillin-treated control groups were included. Deaths were noted as above.

A progressive increase in total and 24-hour mortality was observed in animals treated with hydrocortisone and methicillin or with methicillin alone when initial therapy was delayed from 8 to 14 hours after infection (Table IV). In no instance was the mortality significantly different, however, between paired groups of animals. Hydrocortisone treatment did not influence the bacterial counts in blood or viscera of rabbits also treated with methicillin when compared with counts in animals treated only with methicillin.

Effect of varying hydrocortisone dose upon lethality. Staphylococcal infection was produced in groups of rabbits as described above. Hydrocortisone therapy in doses of 5,20 , or $40 \mathrm{mg}$ per $\mathrm{kg}$ was initiated concurrently with methicillin 12 hours after the onset of infection. The same hydrocortisone doses were repeated twice, as before. Untreated and methicillin-treated control groups were included. The time of death of the animals was recorded.

Almost all untreated animals succumbed (96\%), and $63 \%$ of deaths occurred within 24 hours ( Table VI). The group treated only with methicillin had a total mortality of $54 \%$. Therapy with hydrocortisone in doses of 5,20 , or $40 \mathrm{mg}$ per $\mathrm{kg}$ resulted in total mortality of 42,58 , and $66 \%$, respectively. The differences in total and 24-hour

TABLE VI

Effect of dose of hydrocortisone upon mortality rate of rabbits with methicillin-treated $S$. aureus infection

\begin{tabular}{|c|c|c|c|c|c|c|c|c|}
\hline \multirow{2}{*}{ Group* } & \multirow{2}{*}{$\begin{array}{c}\text { No. of } \\
\text { animals }\end{array}$} & \multicolumn{6}{|c|}{ Deaths and per cent mortality $\dagger$} & \multirow{2}{*}{$\begin{array}{c}\text { Total per cent } \\
\text { mortality }\end{array}$} \\
\hline & & \multicolumn{2}{|c|}{0 to 24 hours } & \multicolumn{2}{|c|}{24 to 48 hours } & \multicolumn{2}{|c|}{48 to 120 hours } & \\
\hline $\begin{array}{l}\text { Control } \\
\text { Meth } \\
\text { Meth }+ \text { H, } 5 \\
\text { Meth + H, } 20 \\
\text { Meth + H, 40 }\end{array}$ & $\begin{array}{l}24 \\
24 \\
24 \\
24 \\
24\end{array}$ & $\begin{array}{r}15 \\
8 \\
9 \\
10 \\
13\end{array}$ & $\begin{array}{l}63 \\
33 \\
38 \\
42 \\
54\end{array}$ & $\begin{array}{l}5 \\
1 \\
1 \\
4 \\
1\end{array}$ & $\begin{array}{r}21 \\
4 \\
4 \\
16 \\
4\end{array}$ & $\begin{array}{l}3 \\
4 \\
0 \\
0 \\
2\end{array}$ & $\begin{array}{r}12 \\
17 \\
0 \\
0 \\
8\end{array}$ & $\begin{array}{l}96 \\
54 \\
42 \\
58 \\
66\end{array}$ \\
\hline
\end{tabular}

* Meth = methicillin $; \mathrm{H}=$ hydrocortisone, dose in milligrams per kilogram. All therapy initiated 12 hours after inception of the staphylococcal infection.

$t$ Indicated jas Jin Table II. 
TABLE VII

Effect of phenoxybenzamine administered before or during infection upon mortality in methicillin-treated staphylococcal infection

\begin{tabular}{|c|c|c|c|c|c|c|c|c|}
\hline \multirow[b]{2}{*}{ Group* } & \multirow{2}{*}{$\begin{array}{c}\text { No. of } \\
\text { animals }\end{array}$} & \multicolumn{6}{|c|}{ Deaths and per cent mortality $\dagger$} & \multirow{2}{*}{$\begin{array}{l}\text { Total per cent } \\
\text { mortality }\end{array}$} \\
\hline & & \multicolumn{2}{|c|}{0 to 24 hours } & \multicolumn{2}{|c|}{24 to 48 hours } & \multicolumn{2}{|c|}{48 to 120 hours } & \\
\hline Control & 20 & 12 & 60 & 4 & 20 & 2 & 10 & 90 \\
\hline $\operatorname{Meth}(12)$ & 20 & 8 & 40 & 1 & 5 & 1 & 5 & 50 \\
\hline Meth (12), & 20 & 0 & 0 & 0 & 0 & 2 & 10 & 10 \\
\hline $\begin{array}{c}\operatorname{Meth}(12), \\
D(+6)\end{array}$ & 20 & 9 & 45 & 2 & 10 & 1 & 5 & 60 \\
\hline
\end{tabular}

$*$ Meth $=$ methicillin $; \mathrm{D}=$ phenoxybenzamine, $1.0 \mathrm{mg}$ per $\mathrm{kg}$ iv. Numbers in parentheses refer to time of treatment in hours before $(-)$ or after $(+)$ inception of infection.

$t$ Indicated as in Table I.

mortality between the three hydrocortisone-treated groups were not significant and were similar to the mortality of groups that received methicillin alone. There was increasing mortality at 24 hours in groups treated with increasing doses of hydrocortisone $(38,42$, and $54 \%$, respectively), but these differences were not significant.

Effect of phenoxybenzamine upon lethality. The following experiment was designed to investigate the effect of phenoxybenzamine administered before infection upon the mortality rate in methicillin-treated staphylococcal infection.

Phenoxybenzamine was administered intravenously to groups of rabbits 1 hour before inception of staphylococcal sepsis. At 10,12 , or 14 hours after onset of infection methicillin therapy was initiated in the phenoxybenzamine-pretreated groups and in methicillin-treated controls as before. Untreated control animals were also included in the experiment.

When methicillin therapy was initiated 10 hours after infection in a phenoxybenzamine-pretreated group, the resulting total mortality was 5\% (Table IV). In the animals treated with methicillin alone the total mortality was $50 \%$, a significantly higher value. The mortality at 24 hours $(5 \%)$ was also significantly lower in the phenoxybenzamine-pretreated group. The institution of methicillin therapy at 12 hours of infection in the phenoxybenzamine-pretreated group resulted in 24hour and over-all mortalities of 5 and $10 \%$, respectively. Each of these values is significantly lower than in the corresponding methicillin-treated control group. Delay in the institution of methicillin therapy until the fourteenth hour in phenoxybenzamine-pretreated animals resulted in no protection against total or 24-hour mortality.
Effect of time of phenoxybenzamine administration upon lethality. Phenoxybenzamine was administered to a group of rabbits 1 hour before the initiation of staphylococcal infection. The same dose was administered to a second group 6 hours after onset of infection. After 12 hours of infection, methicillin therapy was begun in both phenoxybenzamine-treated groups and in a methicillin-treated control group. Appropriate untreated controls were included. Mortality was recorded as previously noted.

Untreated staphylococcal infection resulted in death of $90 \%$ of the animals, with the majority (60\%) dying within 24 hours after infection (Table VII). Administration of methicillin at 12 hours resulted in the death of $50 \%$ of the rabbits, $40 \%$ within the first 24 hours. The group that received phenoxybenzamine at 6 hours and methicillin beginning at 12 hours after infection had a $60 \%$ mortality, $45 \%$ within the first 24 hours. When methicillin was initiated after 12 hours of infection in the group that had been treated before infection with phenoxybenzamine, the total mortality was $10 \%$. There were no deaths within the first 24 hours of infection. The mortality rates in the phenoxybenzamine-pretreated group were significantly lower than the 24-hour and total mortalities of the groups similarly treated with methicillin alone. Administration of phenoxybenzamine at the sixth hour of infection was without effect upon mortality.

Phenoxybenzamine treatment did not influence the bacterial counts in blood or viscera at 4,8 , and 12 hours of infection when animals were sacrificed, in a separate study, at these times. 


\section{Discussion}

The infections employed in the present experiments provide models for study of the pathophysiology and therapy of overwhelming infection under controlled conditions. Experimental pneumococcal infection results in death not prevented by penicillin therapy given after a critical period of time. This resembles the ineffectiveness of antibiotic treatment of pneumococcal bacteremia in human beings; the death rate occurring in the first 5 days of infection is not influenced by antibacterial treatment $(1,2)$. Similarly, in rabbits, early deaths are not prevented by penicillin administered 4 or more hours after the onset of disease (3).

In the rabbit, early deaths have been shown to be related to circulatory insufficiency and to bacteremia of at least $10^{6}$ pneumococci per $\mathrm{ml}$ within 4 hours of infection (3). This relationship of bacteremia to mortality has been observed in other infections of man and experimental animals, including pneumococcal pneumonia (17), bubonic plague (4), acute staphylococcal infection (18), anthrax (5), and coliform bacteremia (19). Treatment of experimental pneumococcal sepsis with penicillin may terminate or markedly reduce bacteremia, but the animal may succumb (3). Evidently, potentially lethal or irreversible damage may develop early in infection, and elimination of most or all bacteria after this has occurred is ineffective in preventing death. The specific nature of the lesions associated with the irreversible stage of infection is not fully understood, but acute progressive circulatory insufficiency probably plays a role in causing death (3).

Staphylococcal infection shares many basic characteristics with lethal pneumococcal bacteremia in the rabbit. Untreated, the infection proved almost invariably fatal. The majority of the animals succumbed in the first 24 hours. Large doses of a specifically active antimicrobial drug, methicillin, administered after the tenth hour of the infection failed to prevent the death of $50 \%$ of the rabbits. Most of the deaths expected to occur within 24 hours of onset of disease could not be averted by the drug, even when given in massive amounts. Evidently the derangements responsible for the fatal outcome were produced as early as the tenth hour of infection. The specific nature of the lesions associated with irreversibility of the infection again are not understood, but in this model progressive circulatory insufficiency has not been found (16).

Adrenal cortical hormones have an antipyretic action, reduce the inflammatory reaction, and ameliorate the subjective manifestations of many diseases (12-15). It has been stated that the use of adrenal corticosteroids may frequently be lifesaving in seemingly hopeless cases of severe infection (20-22), that these agents may "buy time" by sustaining life until the action of the antimicrobial agent controls the infection (23-25). Many studies, however, have failed to document any lowering of mortality by combined adrenal corticosteroid-antimicrobial therapy in a wide variety of acute nontuberculous bacterial infections (22, 26-28).

In the present studies, the ability of combined hydrocortisone-penicillin therapy to prevent deaths from fulminant pneumococcal infection in rabbits not preventable by penicillin alone was clearly demonstrated. This effect of hydrocortisone doubled the period of time after onset of infection during which the initiation of penicillin therapy prevented death. The protective effect of hydrocortisone was demonstrated only in the animals expected to die in the first 24 hours of infection and seemed to be related to the dose administered. The exact mechanisms by which hydrocortisone improved survival in acute pneumococcal sepsis in rabbits, however, are unknown.

Prevention of death by pharmacologic doses of hydrocortisone was probably not related to correction of adrenal insufficiency. Melby and Spink (29) and Bassфe, Aarskog, Thorsen, and St $\varnothing d$ (30) have shown that plasma cortisol levels were increased in bacteremic shock (29). Determinations of the adrenal responsiveness of rabbits with pneumococcal infection were not performed, but it seems probable that there was increased corticosteroid secretion. The adrenal cortex in animals dying from prieumococcal sepsis showed only hydropic change in the fasicular zone consistent with increased secretion of glucocorticoids (31).

There is a difference in the effect of high doses of penicillin upon the rate of termination of pneumococcal bacteremia in rabbits treated before or after the fourth hour of infection (3). Penicillin administered before the fourth hour causes a rapid 
termination of bacteremia, whereas the same dose given after the fourth hour results in a gradual decrease in numbers of viable organisms in the blood. This difference was related to variations in the effect of penicillin upon lethality when administered early or late in the infection (3). The reasons for the difference in the effect of penicillin upon pneumococcal bacteremia when given early or late in the infection are not completely known. It might be presumed that hydrocortisone when administered with penicillin enabled survival by influencing the action of penicillin upon pneumococci, but this was not demonstrated, indicating that the ability of hydrocortisone to prevent death was not attributable to an effect upon the antibacterial action of penicillin.

Hemodynamic alterations with decreasing cardiac output and peripheral pooling of blood (3) begin early in pneumococcal sepsis in the rabbit. Progressive intense vasoconstriction serves to sustain the blood pressure at nearly normal levels until the terminal stage. These alterations in cardiovascular parameters are similar to those observed in many cases of bacteremic shock in man $(32,33)$. Whether hydrocortisone prevents death in the rabbit by a direct action upon the circulatory system to reverse the hemodynamic abnormalities is not known, but this remains a possibility. It has been demonstrated that pharmacologic doses of glucocorticoids lead to increased cardiac output and decreased total peripheral resistance of normal humans and those in shock (34). In animals also, pharmacologic doses of hydrocortisone lead to an increased arterial blood flow and decreased vascular resistance (35). These actions would appear to have the potential ability, at least, to counteract the hemodynamic abnormalities in pneumococcal bacteremia in the rabbit.

Neither low (5 mg per $\mathrm{kg}$ ) nor high (40 mg per $\mathrm{kg}$ ) doses of hydrocortisone prevented death from staphylococcal sepsis, and this was unexpected. The failure of hydrocortisone to protect against death was not related to interference with the antibacterial action of methicillin. There was, however, a suggestive increase in mortality with increasing hydrocortisone dose. Despite the lack of unequivocal evidence of a detrimental effect of hydrocortisone therapy upon the outcome of antibiotic-treated severe staphylococcal infection, a cautious attitude toward this problem seems justified. As the basic lesions responsible for death in most acute bacterial infections are obscure, it is possible that different mechanisms may contribute to death in the various bacterial diseases. Accordingly, it would be unwise to assume that adrenal corticosteroids should have equal lifesaving value in all acute bacterial infections.

Whether the lack of beneficial effect of hydrocortisone is related to different hemodynamic alterations in staphylococcal as compared with pneumococcal sepsis in the rabbit is unknown. In lethal staphylococcal sepsis in rabbits the early stages are characterized by increased cardiac output and diminished total peripheral resistance, opposite findings to those observed in pneumococcal infection (16).

There is a possible detrimental role of excessive vasoconstriction upon the outcome of shock (36, 37). Vasoconstriction after noxious stimuli such as hemorrhage and trauma is a fundamental physiologic response that tends to maintain blood pressure and flow to vital organs. This circulatory adjustment is achieved at the expense of diminished blood flow to the kidney and splanchnic bed. Prolonged vasoconstriction with diminished blood flow and hypoxia in these areas may be related to the development of renal failure and irreversibility of shock (35). The ability of alpha-adrenergic blocking agents such as phenoxybenzamine (PBZ) to enhance survival of animals in shock due to hemorrhage, trauma, and gram-negative bacterial endotoxins is accepted $(7,8,10,11)$. PBZ inhibits vasoconstriction by blocking the action of catecholamines at alpha-adrenergic receptor sites in the walls of blood vessels (38). Despite usage by several investigators there has been little evidence of any lifesaving action of phenoxybenzamine in human shock, particularly that associated with infection $(36,39-41)$.

The previous observation of progressive vasoconstriction and its possible deleterious role in lethal pneumococcal infection in rabbits suggested a trial of $\mathrm{PBZ}$ as adjunctive therapy of this and other fulminant infections ( 3 ). In experiments using animal models, maximal protection by $\mathrm{PBZ}$ against mortality has more often been observed when the drug was administered before the induction of shock. The reasons for this phenomenon are not known, but the increased blood volume 
observed under these circumstances may be responsible (36). This premise awaits substantiation in the infections studied here. Lowering of mortality has also been reported, although apparently less commonly, when the drug is administered after the onset of shock (42).

PBZ administered as pre- or postinfection therapy produced no alteration in mortality of penicillin-treated pneumococcal bacteremia. In view of the known hemodynamic abnormalities in fatal pneumococcal bacteremia in rabbits, these results are surprising and not readily explained. If the protective action of hydrocortisone in pneumococcal bacteremia were related to its vasodilator effects, one would have expected PBZ to affect mortality in the same favorable manner. There is no doubt, however, that in the doses employed (1.0 $\mathrm{mg}$ per $\mathrm{kg}$ ) $\mathrm{PBZ}$ produced potent alpha-adrenergic blockade. Such animals survive many times the lethal intravenous dose of epinephrine and exhibit classical "epinephrine reversal" of blood pressure (38). The rabbits treated with PBZ before onset of infection became lethargic, and profound dilatation of the ear blood vessels was invariably observed.

The administration of $\mathrm{PBZ}$ before the onset of staphylococcal infection prolonged the period during which initiation of methicillin therapy prevented death. Mortality was strikingly lower in the PBZ-pretreated groups of rabbits that received methicillin beginning 10 or 12 hours after infection than in corresponding groups treated only with methicillin. Administration of $\mathrm{PBZ}$ after onset of infection combined with methicillin therapy did not have the same protective effect against death. Survival in these animals was no better than in animals treated only with methicillin.

The mechanisms by which $\mathrm{PBZ}$ exerts its protective action are unknown. There is no evidence that it alters the spread or proliferation of staphylococci within the host. Quantitative cultures revealed no differences in the numbers of staphylococci in the blood and vital organs of control or PBZ-pretreated animals.

It is difficult to relate the protective effects of the drug to hemodynamic changes produced by the staphylococcal infection. Increased cardiac output and pronounced vasodilatation expressed as diminished total peripheral resistance was the usual finding during the first 8 hours of staphylococcal sepsis in the rabbit (16). The major pharmacologic action of $\mathrm{PBZ}$ is to prevent vasoconstriction and promote vasodilatation with consequent increased tissue blood flow. Whether vasoconstriction can occur in some important vascular bed to produce changes ultimately responsible for death despite a reduction in over-all peripheral resistance is unknown but seems unlikely. The possibility that phenoxybenzamine may improve survival by antagonizing the action of staphylococcal alpha toxin was considered, but preliminary studies have failed to demonstrate that PBZpretreated rabbits are protected from the lethal action of this toxin.

\section{Summary}

The effects of antibacterial treatment combined with administration of hydrocortisone or phenoxybenzamine upon death from pneumococcal and staphylococcal infection in rabbits has been investigated. Penicillin given after the fourth hour of pneumococcal sepsis does not prevent deaths expected to occur within 24 hours in untreated animals. Hydrocortisone combined with penicillin treatment prevents deaths not prevented by the antibiotic alone. Hydrocortisone was effective in preventing death from pneumococcal sepsis when given in doses of $20 \mathrm{mg}$ per $\mathrm{kg}$ or more before the tenth hour of infection. This effect of the corticoid was not associated with changes in the antibacterial effects of penicillin. Hydrocortisone had no beneficial effect upon the mortality rate in staphylococcal infection treated with methicillin.

Phenoxybenzamine pretreatment of rabbits with staphylococcal infection given methicillin late in the course of disease prevented deaths ordinarily expected to occur and not prevented by methicillin alone. Phenoxybenzamine treatment given with methicillin after onset of infection, however, did not reduce the mortality rate. Phenoxybenzamine pretreatment of rabbits with pneumococcal infection given penicillin late in the course of disease did not prevent deaths expected to occur and not prevented by penicillin alone.

\section{References}

1. Austrian, R. The current status of bacteremic pneumococcal pneumonia. Re-evaluation of an under- 
emphasized clinical problem. Trans. Ass. Amer. Phycns 1963, 76, 117.

2. Austrian, R., and J. Gold. Pneumococcal bacteremia with especial reference to bacteremic pneumococcal pneumonia. Ann. intern. Med. 1964, 60, 759.

3. Perry, J. E., and L. E. Cluff. Manifestations of fatal pneumococcal infection in rabbits. J. Lab. clin. Med. 1963, 62, 549.

4. McCrumb, F. R., Jr., A. Larson, and K. F. Meyer. The chemotherapy of experimental plague in the primate host. J. infect. Dis. 1953, 92, 273.

5. Smith, H., and J. Keppie. Studies on the chemical basis of the pathogenicity of Bacillus anthracis using organisms grown in vivo in Mechanisms of Microbial Pathogenicity, 5th Symposium of the Society for General Microbiology, J. W. Howie and A. J. O'Hea, Eds. New York, Cambridge University Press, 1955, p. 126.

6. Daniels, W. B. Cause of death in meningococcic infection. Analysis of 300 fatal cases. Amer. J. Med. 1950, 8, 468.

7. Baez, S., S. G. Srikantia, and B. Burack. Dibenzyline protection against shock and preservation of hepatic ferritin systems. Amer. J. Physiol. 1958, 192, 175.

8. Nickerson, M., and S. A. Carter. Protection against acute trauma ad traumatic shock by vasodilators. Canad. J. Biochem. 1959, 37, 1161.

9. Connolly, J. E. The use of adrenal cortical compounds in hemorrhagic shock. J.-Lancet. 1959, $79,460$.

10. Hakstain, R. W., L. G. Hampson, and F. N. Gurd. Pharmacological agents in experimental hemorrhagic shock. Arch. Surg. 1961, 83, 335.

11. Lillehei, R. C., and L. D. MacLean. Physiological approach to successful treatment of endotoxin shock in the experimental animal. Arch. Surg. 1959, 78, 464.

12. Kass, E. H., and M. Finland. Adrenocortical hormones in infection and immunity. Ann. Rev. Microbiol. 1953, 7, 361.

13. Kass, E. H., and M. Finland. Adrenocortical hormones and the management of infection. Ann. Rev. Med. 1957, 8, 1.

14. Kass, E. H., and M. Finland. Corticosteroids and infections. Advanc. intern. Med. 1958, 9, 45.

15. Robinson, H. J. Adrenal steroids and resistance to infection. Antibiot. and Chemother. 1960, 7, 199.

16. Robson, H. G., and L. E. Cluff. Circulatory studies in experimental staphylococcal infection. To be published.

17. Sutton, A. C., and C. E. Sevier. A study of the bacteremia in lobar pneumonia. Bull. Johns Hopk. Hosp. 1917, 28, 315.

18. Butler, E. C. B., and F. C. O. Valentine. Further observations on acute staphylococcal infection. Lancet 1943, 1, 194.

19. Geller, P., E. R. Merrill, and E. Jawetz. Experimental studies on bacterial contamination of bank blood. II. Observations on bacteremia in mice and the influence of antibiotics in preventing death. J. Lab. clin. Med. 1955, 45, 943.

20. Bodey, G. P., B. A. Nies, N. R. Mohberg, and E. J. Freireicl. The effect of adrenal corticosteroid therapy on infections in acute leukemia. Amer. J. med. Sci. 1965, 250, 162.

21. Weil, M. H., H. Shubin, and M. Biddle. Shock caused by gram-negative microorganisms. Analysis of 169 cases. Ann. intern. Med. 1964, 60, 384.

22. Cooperative study group. The effectiveness of hydrocortisone in the management of severe infections. A double-blind study. J. Amer. med. Ass. 1963, 183, 462.

23. Jahn, J. P., L. Boling, T. R. Meagher, H. H. Peterson, G. Thomas, B. M. Fisher, A. E. Thill, W. A. Leovy, H. E. Balch, and L. W. Kinsell. The combination of ACTH-cortisone-hydrocortisone with antibiotics in the management of overwhelmingly severe infections. J. Pediat. 1954, 44, 640.

24. Kinsell, L. W., and J. P. Jahn. The use of corticoids in association with antibiotics in the management of unusually severe infections. Ann. N. Y. Acad. Sci. 1955, 61, 397.

25. Kinsell, L. W., and J. P. Jahn. Combined hormonalantibiotic therapy in patients with fulminating infection. Arch. intern. Med. 1955, 96, 418.

26. Lepper, M. H., and H. W. Spies. A clinical study of the use of cortisone, hydrocortisone and corticotropin in the treatment of patients with infections in Antibiotics Annual, H. Welch and F. MartiIbanez, Eds. New York, Medical Encyclopedia, 1957, p. 447.

27. Wasz-Höckert, O. Steroid therapy in acute, lifethreatening infections. Acta Pediat. (suppl.) 1963, 140, 79.

28. Hansted, C., P. Paerregaard, and E. Thamdrup. Steroid therapy in acute life-threatening infections. Acta. Pediat. (suppl.) 1963, 140, 80.

29. Melby, J. C., and W. W. Spink. Comparative studies on adrenal cortical function and cortisol metabolism in healthy adults and in patients with shock due to infection. J. clin. Invest. 1958, 37, 1791.

30. Bassфe, H. H., D. Aarskog, T. Thorsen, and K. F. St $\varnothing$ a. Cortisol production rate in patients with acute bacterial infection. Acta med. scand. 1965, 177, 701.

31. Robson, H. G., and L. E. Cluff. Unpublished observations.

32. Udhoji, V. N., M. H. Weil, M. P. Sambhi, and L. Rosoff. Hemodynamic studies on clinical shock associated with infection. Amer. J. Med. 1963, 34, 461.

33. Udhoji, V. N., and M. H. Weil. Hemodynamic and metabolic studies on shock associated with bacteremia. Observations on 16 patients. Ann. intern. Med. 1965, 62, 966.

34. Sambhi, M. P., M. H. Weil, and V. N. Udhoji. Acute pharmacodynamic effects of glucocorticoids. Cardiac output and related hemodynamic changes in 
normal subjects and patients in shock. Circulation 1965, 31, 523.

35. Lillehei, R. C., J. K. Longerbeam, and J. C. Rosenberg. The nature of irreversible shock: its relationship to intestinal changes in Shock, Pathogenesis and Therapy, K. D. Bock, Ed. New York, Academic Press, 1962, p. 106.

36. Nickerson, M. Drug therapy of shock in Shock, Pathogenesis and Therapy, K. D. Bock, Ed. New York, Academic Press, 1962, p. 356.

37. Nickerson, M. Factors of vasoconstriction and vasodilation in shock. J. Mich. med. Soc. 1955, 54, 45.

38. Nickerson, M. The pharmacology of adrenergic blockade. Pharmacol. Rev. 1949, 1, 27.
39. Wilson, R. F., D. V. Jablonski, and A. P. Thal. The usage of Dibenzyline in clinical shock. Surgery 1964, 56, 172.

40. Eckenhoff, J. E., and L. H. Cooperman. The clinical application of phenoxybenzamine in shock and vasoconstrictive states. Surg. Gynec. Obstet. 1965, 121, 483.

41. Lillehei, R. C., J. K. Longerbeam, J. H. Bloch, and W. G. Manax. The nature of irreversible shock: experimental and clinical observations. Ann. Surg. 1964, 160, 682.

42. Vick, J. A. Endotoxin shock in the primate: treatment with phenoxybenzamine. J. clin. Invest. 1964, $43,279$. 